\title{
Analysis of the effect of renal excretory system cooling during thermal radiofrequency ablation in an animal model
}

André Meireles, Khaled Ahmed Taha Neto, Lísias Nogueira Castilho, Giuseppe D’Ippolito, Leonardo Oliveira Reis

Faculty of Medicine, Pontifical Catholic University of Campinas (AM, KATNeto, LOR); Radium Institute (LNC, LOR), Campinas; Federal University of São Paulo, Unifesp (GDI), São Paulo and School of Medical Sciences, University of Campinas, Unicamp, (LOR), Campinas, SP, Brazil

\section{ABSTRACT}

Objective: Analysis of renal excretory system integrity and efficacy of radiofrequency ablation with and without irrigation with saline at $2^{\circ} \mathrm{C}(\mathrm{SF} 2)$.

Materials and Methods: The median third of sixteen kidneys were submitted to radiofrequency (exposition of $1 \mathrm{~cm}$ ) controlled by intra-surgical ultrasound, with eight minutes cycles and median temperature of $90^{\circ} \mathrm{C}$ in eight female pigs. One excretory renal system was cooled with $\mathrm{SF} 2$, at a $30 \mathrm{ml} / \mathrm{min}$ rate, and the other kidney was not. After 14 days of post-operatory, the biggest diameters of the lesions and the radiological aspects of the excretory system were compared by bilateral ascending pyelogram and the animals were sacrificed in order to perform histological analysis.

Results: There were no significant differences between the diameters of the kidney lesions whether or not exposed to cooling of the excretory system. Median diameter of the cooled kidneys and not cooled kidneys were respectively (in $\mathrm{mm}$ ): anteroposterior: 11.46 vs. 12.5 ( $p=0.23$ ); longitudinal: 17.94 vs. 18.84 ( $p=0.62)$; depth: 11.38 vs. 12.25 $(p=0.47)$. There was no lesion of the excretory system or signs of leakage of contrast media or hydronephrosis at ascending pyelogram.

Conclusion: Cooling of excretory system during radiofrequency ablation does not significantly alter generated coagulation necrosis or affect the integrity of the excretory system in the studied model.

\section{ARTICLE INFO}

\section{Key words:}

Carcinoma, Renal Cell; Ablation Techniques; Therapeutics; Hyperthermia, Induced; Catheters

Int Braz J Urol. 2014; 40: 93-9

Submitted for publication: March 04, 2013

Accepted after revision:

September 17, 2013

\section{INTRODUCTION}

The rationale of the use of radiofrequency (RF) in medicine is based on the generation of heat in order to destroy cells.

At temperatures $60-100^{\circ} \mathrm{C}$ range, there is instant protein coagulation that frequently evolves to coagulation necrosis (1). Consequently, the ideal working temperature varies from 50 to $100^{\circ} \mathrm{C}$ throughout the target tissue (2).
However, heat is heterogeneously distributed. Generally, there is a major heating close to the needle and lower temperature in the outer tissues, since there is no uniform heat conductivity to the surroundings (2). A simple needle is capable to produce a maximum lesion of $1.6 \mathrm{~cm}$ of diameter (3).

Although not extensively studied, the use of saline in the excretory system before or during radiofrequency ablation may interfere in the heat 
distribution and consequently in the efficacy and complications of the method.

We evaluated the integrity of the excretory system and efficacy of renal radiofrequency in an animal model with and without irrigation of the excretory system, using saline at $2^{\circ} \mathrm{C}$.

\section{MATERIALS AND METHODS}

After approval of the local Ethical Committee in Animal Research (protocol 041/03) and technique standardization during a pilot study using 12 kidneys of 6 animals, 16 kidneys of 8 female pigs free of specific pathogens (SPF - Specific Pathogen Free) of Large White breed, with ages from 54 to 62 days of life, weighting 15.5 to $26 \mathrm{~kg}$, were studied.

The animals were adequately anesthetized (sodic thiopental, $2 \mathrm{mg} / \mathrm{kg}$; midazolam $0.1 \mathrm{mg} / \mathrm{kg}$; alfentanil $0.1 \mathrm{mg} / \mathrm{kg}$ and pancuronium bromete $0.1 \mathrm{mg} / \mathrm{kg}$ ), submitted to oro-tracheal intubation and mechanic ventilation (Takaoka ${ }^{\circledR}$ ) and placed on a horizontal dorsal decubitus. Then, it was performed a median longitudinal laparotomy, the kidneys were identified and the bladder was incised.

One of the ureteral meatus was catheterized with a double-lumen $7 \mathrm{Fr}$ catheter in order to perform cooling using saline at $2^{\circ} \mathrm{C}$ (using a digital thermometer Testo $106-\mathrm{T} 1{ }^{\circledR}$ for control) at a medium flow of $30 \mathrm{ml} / \mathrm{min}$. Eight kidneys were randomly distributed, 4 animals at right and 4 at left, and the perfusion was initiated two minutes before the ablation, as proposed by Margulis et al (4). One of the ports of the catheter was used to infuse and the other to collect the cooled saline.

A generator model 1500 (RITA Medical Systems, Mountain View, California, maximum potency of 150W) was used to apply radiofrequency under direct vision in the medium third of both kidneys of each animal $(n=16)$, using a $1 \mathrm{~cm}$ exposition needle and ultrasound control, keeping a constant distance between the center of the ablation area and the excretory system in all cases. It was used a cycle of 8 minutes and a medium temperature of $90^{\circ} \mathrm{C}$. The catheter was removed and the bladder was sutured.

After ablation was completed, the medium temperature of the liquid that was returning from the double-lumen catheter was $13.5^{\circ} \mathrm{C}$. Animal temperature was controlled intra-rectally and varied from 37 to $37.5^{\circ} \mathrm{C}$.

After 14 days, the integrity of the collecting system was evaluated using bilateral ascending pyelogram in vivo, injecting $5 \mathrm{ml}$ of iodine contrast after incision of the bladder and catheterization of both ureters.

The kidneys were removed and opened (convex part) and the biggest dimensions of the lesion were recorded: longitudinal, anteroposterior and depth, using a digital capiler rule as previously proposed $(5,6)$.

Cellular viability was confirmed by histological aspect and presence of coagulation necrosis after hematoxilin-eosin stain. Next, the animals were sacrificed and the histopathologic exam was performed by a blind examiner, who was not aware of which side was cooled.

The size of the studied population (8 animals, 16 kidneys) was based on a pilot study using 14 animals (28 kidneys) and similar protocols in the literature. The "SAS System for Windows" (Statistical Analysis System), version 6.12. "SAS Institute Inc.", 1989-1996, Cary, NC, USA and the t-Student tests were used to compare the measures. Significance level was 5\% ( $<<0.05)$.

\section{RESULTS}

The sample was quite homogeneous, given the animals weight and the kidney dimensions, with elevated $p$ values (Table-1). There was no lesion of the excretory systems, signs of contrast leakage or hydronephrosis during ascending pyelogram.

All kidneys showed a lesion with a central area of coagulation necrosis, and the tubules and glomerules lost their cellular limits, with intense eosinophilia in the cytoplasm and areas with total destruction of cellular architecture and no nucleus. In the middle of the area of necrosis, some vessels with thrombosis and recanalization were observed, showing that heat ablation also damaged vessels, adding ischemic lesion to the area previously irrigated by those vessels. In the transition area with viable locals, it was possible to identify a well defined circle around the central 
Table 1 - Sample data of the animals submitted to thermoablation using radiofrequency.

\begin{tabular}{lccccc}
\hline & MEDIAN & SD & MIN. & MAX. & P-VALUE \\
\hline Animal $(\mathrm{kg})$ & 21.44 & 3.58 & 15.1 & 26 & \\
High (C) $(\mathrm{mm})$ & 111.38 & 5.7 & 94.5 & 111.7 & \\
High (mm) & 101.39 & 7.24 & 90.3 & 111 & $\mathrm{p}=0.995$ \\
Width (C) (mm) & 50.18 & 4.38 & 44.2 & 56.7 & \\
Width (mm) & 51.69 & 3.78 & 44.9 & 56.7 & $\mathrm{p}=0.232$ \\
Thickness (C) (mm) & 23.86 & 1.56 & 22.3 & 26.9 & \\
Thickness (mm) & 24.63 & 1.86 & 22.6 & 28.1 & $\mathrm{p}=0.329$ \\
\hline
\end{tabular}

$\mathbf{S D}=$ Standard deviation; $\mathbf{M I N}=$ Minimum; $\mathbf{M A X}=$ Maximum; $\mathbf{( C )}=$ Cooled kidney

necrosis. It is a transition area with acute tubular necrosis (ATN), with hypereosinophilia of the tubular cytoplasm, nuclear basophilia and alteration of the glomerular architecture with inflammatory infiltrate. Cell viability in the area is uncertain, and it may or may not show tissue recovery.

There was no significant difference between the groups in terms of area of lesion, whatever considered diameter (Tables 2 and 3).

Media of diameters of lesion of the cooled and not cooled kidneys were, respectively $(\mathrm{mm})$ :

Anteroposterior: 11.46 vs. $12.5(\mathrm{p}=0.23)$

Longitudinal: 17.94 vs. $18.84(\mathrm{p}=0.62)$

Depth: 11.38 vs. 12.25 ( $\mathrm{p}=0.47)$

There were no differences between the closest and the more distant areas in the irrigated kidneys. The microscopic aspects of lesions were very similar, independently of cooling of excretory system. There was no difference at histopathology and coagulation necrosis area between the groups ( $p>0.05)$ (Figure-1).

In the urothelium areas close to the tissue submitted to RF it was observed a light distortion of the urothelial architecture. The umbrella cells, that form the most superficial layer of the urothelium, were bigger in size, vacuolated, suggesting entrance of liquid in the intracellular space due to alteration of permeability. There was also inflammatory process and some areas of subepithelium fibrosis. In some regions there was a massive lost of

Table 2 - Median size of the lesions of cooled and not cooled kidneys (mm).

\begin{tabular}{lccccc}
\hline & MEDIAN & SD & MIN. & MAX. & P - VALUE \\
\hline AP - C & 11.46 & 1.3 & 10 & 13.2 & \\
AP & 12.5 & 2.21 & 9.3 & 16.9 & $p=0.232$ \\
Longitudinal - C & 17.94 & 2.81 & 13.1 & 22.2 & \\
Longitudinal & 18.84 & 3.71 & 13.3 & 25.4 & $p=0.625$ \\
Depth - C & 11.38 & 1.77 & 7.6 & 13.3 & \\
Depth & 12.25 & 2.41 & 7.8 & 15.8 & $p=0.467$ \\
\hline
\end{tabular}

SD = Standard deviation; $\mathbf{M I N}=$ Minimum; $\mathbf{M A X}=$ Maximum; $\mathbf{A P}=$ Anteroposterior; $\mathbf{( C )}=$ = Cooled kidney 
Table 3 - Size of the lesions in each animal ( $\mathrm{mm})$.

\begin{tabular}{lcccccc}
\hline & \multicolumn{3}{c}{ Cooled kidney } & \multicolumn{3}{c}{ Kidney not cooled } \\
\cline { 2 - 7 } & AP & Long. & Depth & AP & Long. & Depth \\
\hline Pig 1 & 11.3 & 17.8 & 13.5 & 10 & 13.1 & 7.6 \\
Pig 2 & 13.2 & 18 & 14.2 & 10 & 17.4 & 11.3 \\
Pig 3 & 12 & 22.5 & 15.8 & 13.2 & 16.6 & 12.7 \\
Pig 4 & 16.9 & 25.4 & 11 & 11.7 & 18.9 & 13.3 \\
Pig 5 & 13.1 & 17.2 & 12.5 & 12.2 & 17.4 & 12 \\
Pig 6 & 13 & 19.7 & 12.1 & 10.2 & 21 & 11.6 \\
Pig 7 & 9.3 & 13.3 & 7.8 & 13 & 22.2 & 12.2 \\
Pig 8 & 11.2 & 16.8 & 11.1 & 11.4 & 16.9 & 10.3 \\
\hline
\end{tabular}

AP = Anteroposterior; Long = Longitudinal

Figure 1: A) external aspect of the lesion; B) Ascending pyelogram without alterations; C) macroscopic aspect of the excretory system; D) Microscopy, 40X, urothelium.

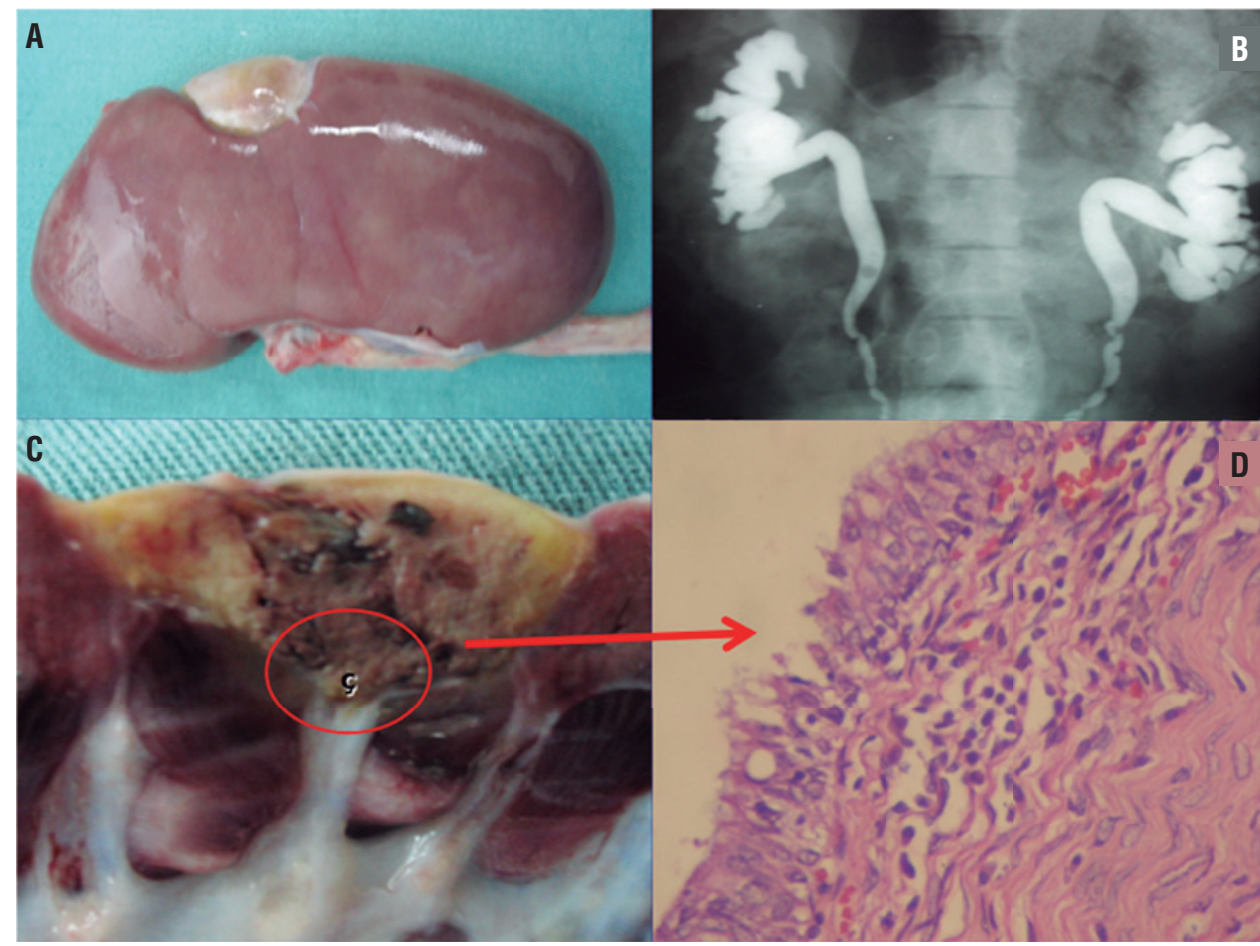


cellular layers, with a single layer of paving stone cells. However, the alterations were discrete without cellular necrosis. Actually the urothelium showed signs of regeneration, with recovery of layers. Microscopic aspects of urothelium were very similar in the kidneys submitted to cooling or not.

\section{DISCUSSION}

Heat lesion of urothelium during thermoablation of renal tumor with radiofrequency is one of the complications of this form of treatment (7).

In the studied model, cooling of excretory system did not alter coagulation necrosis or interfere with the integrity of urothelium after 14 days of surgery, adding data to previous studies that limited evaluation to 74.8 to 107 days of protocol.

In order to define the sample size, we considered the study by Chang et al (8) that used six animals. Also, the present study was based on a pilot protocol that allowed the necessary standardizations with 12 kidneys of 6 animals, finishing with 28 kidneys and 14 animals. There was also intra-individual pairing: the same animal was submitted to two different forms of RF ablation allowing the use of a small population in order to obtain relevant statistical data (4), sparing experimental animals according to the best practices of animal experimentation.

We used ablation under direct vision, since porcine perirenal fat is scarce (9), favoring lesion of neighbor structures. In humans, this layer is less than $1 \mathrm{~cm}$ of thickness, with better protection and thermal isolation during RF ablation.

We defined a median temperature of $90^{\circ} \mathrm{C}$, capable to destroy tissues (1) during eight minutes, in one cycle, since this pattern proved to be effective during the pilot study.

The way to evaluate the renal lesion created by RF is also not standardized in literature, since it is quite irregular. Some use a formula to calculate the volume of an ellipse (10), others use only the greatest diameter (11) or both diameters multiplied. We believe that the analysis of the three biggest diameters (longitudinal, anteroposterior and depth), as described by Gettman and Rehman $(5,6)$ is more accurate since allows tridimensional analysis of the lesion.
Lesions have a wedge form, probably due to the segmental pattern of renal circulation, with the flow running from the medulla to the cortex. When central flow is interrupted, the area downstream becomes ischemic and suffers infarct. So the tissue necrosis after RF ablation is obtained not only by heat but also by occlusion of vessels, followed by ischemia. The present study shows that the longitudinal diameter is around $6 \mathrm{~mm}$ greater than the anteroposterior and depth diameters. These data were obtained in normal renal tissue. Maybe in tumor tissue the interaction with RF may be different.

The organ to be submitted to RF may be accessed by laparotomy, laparoscopy or percutaneously, the latter cheaper and less aggressive, that can be performed under local anesthesia and sedation (12). The advantage of ablation by laparotomy or laparoscopy, using an intra-surgical ultrasound is the capacity of direct visualization of the tumor and possible concurrent tumor lesions.

Image control during the procedure is fundamental to avoid lesions of neighborhood organs or even incomplete ablation. Unfortunately, there is still no image method able to fulfill this task and identifies the needle and its eventual repositioning (13).

In the present study, confirmation of cellular viability by histopathology is justified since there is no adequate correlation of radiologic image and histopathology after renal radiofrequency (14). The median temperature of the returning liquid by the double-lumen catheter of $13.5^{\circ} \mathrm{C}$ is in accordance to other experiments in literature $(4,15)$.

Anidjar et al (16), in 1999, studied the experimental model of heat ureteral lesion in pigs, coagulating all median upper ureter circumference using an electrical scalpel. After a median interval of 9 days, there was a marked hydronephrosis in all animals. Besides, current literature about lesions of excretory systems during tumor ablation by radiofrequency shows that in the majority of cases the lesion occurs in the first 15 days after the procedure $(7,17)$. Also, maximal extension of necrosis is detected after 7 days of RF $(7,18)$, which corroborates our analysis after 14 days of protocol. 
In relation to the absence of difference of the size of lesion whether the kidney was cooled or not, Landman et al experiment (15) showed that during cooling performed exclusively by ureteral catheter, intraparenchymal temperature was not altered, since renal temperature depends mainly of arterial flow, that keeps the organ stable, as long as the flow is not obstructed. In that manner, it is possible to understand the results, independently of the cooling effect of the excretory system, proved but not completely explained.

On the other hand, although not statistically significant, it is important to observe a constant difference of $1 \mathrm{~mm}$ less in the media of the lesion diameters of the cooled kidneys (Tables 2 and 3). It is important to confirm the clinical importance of this aspect since it can alter the efficacy of RF during cooling of excretory system of human beings. Long term studies with oncological data are necessary (19).

Hwang et al (20) also showed evidences, although fragile, that cooling of excretory system may alter the clinical results of RF. They observed a variation of the median diameter of the ablated area of cooled kidneys in relation to those not cooled after 7 days of post-operatory: 7.5\% ( $\mathrm{P}=$ 0.002) and 9.6\% ( $\mathrm{P}=0.008)$, respectively.

The size of the lesion is not constant, and each situation is different in terms of interaction with the energy source and tissue response. The variation of the lesion size probably is related to the high blood flow of kidneys (15).

The comparison of the results of the present study with those related to biliary duct cooling during thermoablation with RF (21) shows that cooling is capable to reduce significantly the possibility of fistula or stenosis of biliary ducts. Some possible explanations can be discussed why the same was not observed in the urothelium. First, the epithelium linings are different. Second, urine and bile components are different and may have different electrical proprieties. And finally, space disposition of the biliar tree and of the urinary tract are different.

In the kidney, major complications occur after lesion of ureter or pelvic-ureteral junction, away from the renal cortex. In the liver, intra-hepatic lesion of the biliar ducts may present significant damages.
Also, the exposition of the needle was smaller in the present study $(1 \mathrm{~cm})$ in relation to previous ones $(3 \mathrm{~cm})(20)$ and intentionally was not place upon the excretory tract (7). So our results are related to lesions close to the urothelium and further studies are needed for more profound lesions with bigger damage to the urothelium and to test the consequences of cooling.

Some aspects differentiate our study: the use of in vivo retrograde pyelogram (most studies used ex vivo (20)), lower morbidity of retrograde cooling in relation to antegrade (that requires nephrostomy), avoiding dissemination, bleeding and additional trauma (20), use of hystopathology to measure the lesion, ablation under direct vision and use of intrasurgical ultrasound in order to maximize accuracy of ablation, data collection and hystological interpretation without knowledge of cooling, avoiding bias and the use of saline in order to avoid complications in the event of leakage and absorption.

Main limitations of our study are the absence of median and long terms data and not use of an oncological model, as occurred with other studies $(4,7,20)$ as well as the low exposition of the needle $(1 \mathrm{~cm})$ avoiding lesion of the excretory tract, although the clinical significance of the lesions is questionable $(4,7,20)$.

\section{CONCLUSIONS}

Cooling of the excretory tract during ablation of renal parenchyma did not alter significantly the integrity of the urothelium and did not interfere with the area of coagulation necrosis generated by $\mathrm{RF}$ in relation to conventional ablation, without cooling, microscopically and radiologically.

\section{CONFLICT OF INTEREST}

None declared.

\section{REFERENCES}

1. Goldberg SN, Gazelle GS, Solbiati L, Livraghi T, Tanabe KK, Hahn PF, et al.: Ablation of liver tumors using percutaneous RF therapy. AJR Am J Roentgenol. 1998; 170: 1023-8. 
2. Goldberg SN, Gazelle GS, Halpern EF, Rittman WJ, Mueller PR, Rosenthal DI: Radiofrequency tissue ablation: importance of local temperature along the electrode tip exposure in determining lesionshape and size. Acad Radiol. 1996; 3: 212-8.

3. Goldberg SN, Gazelle GS, Dawson SL, Rittman WJ, Mueller PR, Rosenthal DI Tissue ablation with radiofrequency: effect of probe size, gauge, duration, and temperature on lesion volume. Acad Radiol. 1995; 2: 399-404.

4. Margulis V, Matsumoto ED, Taylor G, Shaffer S, Kabbani W, Cadeddu JA: Retrograde renal cooling during radio frequency ablation to protect from renal collecting system injury. J Urol. 2005; 174: 350-2.

5. Rehman J, Landman J, Lee D, Venkatesh R, Bostwick DG, Sundaram C.: Needle-based ablation of renal parenchyma using microwave, cryoablation, impedance- and temperature-based monopolarand bipolar radiofrequency, and liquid and gel chemoablation: laboratory studies and review of the literature. J Endourol. 2004; 18: 83-104.

6. Gettman MT, Lotan Y, Corwin TS, Smith TG, Napper CA, Lindberg $G$, et al.: Radiofrequency coagulation of renal parenchyma: comparison of effects of energy generators on treatment efficacy. J Endourol. 2002; 16: 83-8.

7. Brashears JH 3rd, Raj GV, Crisci A, Young MD, Dylewski $D$, Nelson $R$, et al.: Renal cryoablation and radio frequency ablation: an evaluation of worst case scenarios in a porcine model. J Urol. 2005; 173: 2160-5.

8. Chang I, Mikityansky I, Wray-Cahen D, Pritchard WF, Karanian JW, Wood BJ: Effects of perfusion on radiofrequency ablation in swine kidneys. Radiology. 2004; 231: 500-5.

9. Hwang JJ, Walther MM, Pautler SE, Coleman JA, Hvizda J, Peterson J, et al.: Radio frequency ablation of small renal tumors: intermediate results. J Urol. 2004; 171: 1814-8.

10. Burdío F, Güemes A, Burdío JM, Navarro A, Sousa R, Castiella $\mathrm{T}$, et al.: Bipolar saline-enhanced electrode for radiofrequency ablation: results of experimental study of in vivo porcine liver. Radiology. 2003; 229: 447-56. Erratum in: Radiology. 2004; 230: 303.

11. Rendon RA, Gertner MR, Sherar MD, Asch MR, Kachura JR, Sweet J, et al.:Development of a radiofrequency based thermal therapy technique in an in vivo porcine model for the treatment of smallrenal masses. J Urol. 2001; 166: 292-8.

12. Gillams AR: Thermal ablation of liver metastases. Abdom Imaging. 2001; 26: 361-8.

13. Rhim H, Goldberg SN, Dodd GD 3rd, Solbiati L, Lim HK, Tonolini M, Cho OK: Essential techniques for successful radiofrequency thermal ablation of malignant hepatic tumors. Radiographics. 2001; 21: S17-35; discussion S36-9.
14. Weight CJ, Kaouk JH, Hegarty NJ, Remer EM, O'Malley CM, Lane BR, et al.: Correlation of radiographic imaging and histopathology following cryoablation and radio frequency ablation for renal tumors. J Urol. 2008 ; 179: 1277-81; discussion 1281-3.

15. Landman J, Rehman J, Sundaram CP, Bhayani S, Monga $M$, Pattaras JG, et al.: Renal hypothermia achieved by retrograde intracavitary saline perfusion. J Endourol. 2002; 16: $445-9$

16. Anidjar M, Mongiat-Artus P, Brouland JP, Meria P, Teillac P, Le Duc $A$, et al.: Thermal radiofrequency induced porcine ureteral stricture: a convenient endourologic model. J Urol. 1999; 161: 298-303.

17. Johnson DB, Saboorian MH, Duchene DA, Ogan K, Cadeddu $\mathrm{JA}$ : Nephrectomy after radiofrequency ablation-induced ureteropelvic junction obstruction: potential complication and long-term assessment of ablation adequacy. Urology. 2003; 62: 351-2.

18. Schulman CC, Zlotta AR: Transurethral needle ablation of the prostate (TUNA). A new treatment of benign prostatic hyperplasia using interstitialradiofrequency energy. J Urol. 1995; 101: 33-6.

19. Cantwell CP, Wah TM, Gervais DA, Eisner BH, Arellano R, Uppot RN, et al.: Protecting the ureter during radiofrequency ablation of renal cell cancer: a pilot study of retrograde pyeloperfusion withcooled dextrose $5 \%$ in water. J Vasc Interv Radiol. 2008; 19: 1034-40.

20. Hwang SI, Cho JY, Kim SH, Jun SR, Lee HJ, Moon KC, et al.: Protection of the renal collecting system during radiofrequency ablation with antegrade cold dextrose infusion. Radiology. 2010; 256: 759-66.

21. Dominique E, El Otmany A, Goharin A, Attalah D, de Baere T: Intraductal cooling of the main bile ducts during intraoperative radiofrequency ablation. J Surg Oncol. 2001; 76: 297-300. 